\title{
INTEGRATING LAND USE AND TRANSPORT PRACTICE THROUGH SPATIAL METRICS
}

\begin{abstract}
Despite the growing development of tools that can integrate land use and transport, the desired integration is still illusive in daily practice. To address this gap, the current study uses spatial metrics, a set of methods traditionally used for studying changes in the spatial structure of landscapes, which are translated into the domain of transport planning. It examines how spatial metrics can be integrated into "Land Use Transport" strategy-making, and how useful they are according to the practitioners' perceptions. A Light Rail Transit corridor in Granada (Spain) provides the empirical focus of this research. Land use characteristics such as: land use mixing, land use diversity and green areas connectivity were successfully studied using spatial metrics, and they were used to map three "Land Use Transport" strategies: (i) proximity dynamics and non-motorised modes; (ii) modal shift from cars to Light Rail Transit system; (iii) shared spaces between motorised and nonmotorised modes. Practitioners perceived that spatial metrics could improve the "Land Use Transport" strategy-making process in comparison with traditional methods used in practice. However, certain shortcomings related to the usability of spatial metrics are also highlighted and discussed. This study concludes with a reflection on research challenges for adapting spatial metrics to transport practice.
\end{abstract}

Keywords: Corridor; Sustainability; Light Rail; Landscape; FRAGSTATS. 


\section{Introduction}

In the field of transport research there is a growing interest in unravelling the complex relationships between land use and transport (e.g. Bertolini and Djist, 2003; Cervero and Kockelman, 1997; Hrelja, 2015; Van Acker et al., 2007). This is supported by the idea that if the land use and transport sector are reciprocally supportive, important benefits of mobility can be increased (e.g. access to amenities, jobs, etc.), while negative impacts could be reduced (e.g. pollution, congestion, noise, etc.). In particular, Banister (2005, p. 97) discusses six groups of land use factors that are interconnected with transport: settlement size (Hickman and Banister, 2007); urban density (Oakes et al., 2007), land use diversity (Pitombo et al., 2011), urban design (Jones et al., 2007), local accessibility to public transport (Cervero et al., 2009); and the provision of parking (Albert and Mahalel, 2006). While academia eagerly explores how the abovementioned factors affect travel behaviour and the use of different transport modes, the translation of those findings into daily practice is still lagging behind, and shared "Land Use Transport" (LUT) visions and concepts are often absent in practice (e.g. Ewing and Cervero, 2012 Su et al., 2014; Waddell et al., 2007; Te Brömmelstroet and Bertolini, 2008).

Regarding LUT, the lack of spatial perspective during the planning process is seen as one of the crucial barriers. This addresses the need to translate abstract land use characteristics that impact travel behaviour, such as: land use mixing or land use diversity into a more intuitive language for the professional groups in practice (Silva and Pinho, 2010; Soria-Lara et al., 2015; Straatemeier, 2008). If this barrier persists, the desired LUT integration will be very difficult to achieve in practice, especially in the context of emergent communicative planning approaches that demand support decision tools to facilitate the interaction and debate of professional domains (Bertolini et al, 2008; Curtis, 2011; Habermars, 2007). In contrast, if the lack of a LUT spatial perspective is overcome, this can help to reinforce transport practice as a collective process, where different actors and professional groups can more easily deliberate and exchange views in order to effectively design LUT strategies (Te Brömmelstroet and Bertolini, 2010). An important consideration here is to find methods and tools that can provide new insights into the described knowledgepractice gap. 
Spatial metrics, operationalised by the moving-window approach, are shown here as a promising solution. They provide a set of spatial indicators that are traditionally used for studying landscape processes and patterns (Turner, 2005). Over the past years, spatial metrics have been used more frequently in urban studies to characterise urban growth patterns (e.g. Barreira et al., 2015; Aguilera et al., 2014; Herold et al., 2005; Li et al., 2008). However, their effectiveness at the transport practice level is largely unexplored (Soria-Lara et al., 2014).

Accordingly, this paper will explore the following research questions: How could spatial metrics be integrated into LUT strategy-making, and how do practitioners consider their usability and outcome for spatial planning practice? We answered this by applying three spatial metrics (interspersion and juxtaposition index; shannon diversity index; and aggregation index for green areas) on the Light Rail Transit (LRT) corridor in the metropolitan area of Granada (Spain). The aforementioned spatial metrics were used to analyse and study three specific land use characteristics that are strongly related to transport systems, but are not always taken into consideration in transport practice: land use mixing, land use diversity and green areas connectivity. First, the results from spatial metrics were combined to identify and locate three LUT strategies: (i) proximity dynamics and non-motorised modes; (ii) modal shift from cars to LRT; (iii) shared spaces between motorised and nonmotorised modes, on the LRT corridor. Second, a set of practitioners were asked to indicate their views on both the usability and outcomes of spatial metrics for LUT strategy-making.

In the next section, recent academic insights on the use and limitations of spatial metrics in urban studies are discussed. In section 3 , the research method is described, while section 4 presents both the application of the three spatial metrics to the context of Granada and the perceptions of practitioners on their usability and outcomes. This paper closes with several concluding remarks and recommendations for further enquiries. 


\section{Spatial metrics: Definition and limitations in the urban context}

The concept of spatial metrics comes from the application of "landscape metrics" to the context of urban areas. These widely-known landscape analysis tools gained importance during the last decades for analysing spatial characteristics and patterns of urban growth (e.g. Wu et al., 2011; Kaza, 2013), triggering the use of the so-called spatial metrics (Herold et al., 2003; Seto and Fragkias, 2005). According to Herold et al., (2003), spatial metrics can be defined as "measurements derived from the digital analysis of thematic-categorical maps exhibiting spatial heterogeneity at a specific scale and resolution". Consequently, spatial metrics have become a popular tool in urban studies (e.g. Aguilera et al., 2014; Dietzel et al., 2005; Wu et al., 2011).

A literature review of more than 50 publications from ISI web of Knowledge ${ }^{1}$ (Pascual et al., In progress) shows a frequent use of spatial metrics in the following fields:

i) Analysing and describing urban growth patterns at city level (e.g. $\mathrm{Xu}$ et al, 2007; Shrestha et al., 2012; Aguilera et al., 2014). The consulted studies in this field offer abundant insights into aspects related to urban growth, such as: urban sprawl, fragmentation of natural areas, conurbation, etc.

ii) Comparing and classifying different cities across the world (e.g. Taubenböck et al., 2009; Schwarz, 2010). These studies aim at comparing urban growth patterns in different cities according to several spatial characteristics of urban land uses that are measured by spatial metrics.

ii) Simulating urban growth patterns (e.g. Petrov et al., 2009; Aguilera et al., 2011; García et al., 2011; Kong et al., 2012). These studies mainly aim at using spatial metrics to calibrate urban growth simulations, comparing spatial metrics results from simulation models with real urban growth patterns.

Despite the growing application of spatial metrics from "landscape analysis" to the study of urban phenomena, certain shortcomings, negatively affecting the applicability of spatial metrics in urban contexts, can be seen.

\footnotetext{
${ }^{1}$ Relevant journals are e.g. Landscape and Urban Planning; Applied Geography; Computers, Environment and Urban Systems; Landscape Ecology; Ecological Indicators.
} 
First, unlike natural landscapes, the urban context has a vertical variability of land use activities (e.g. shared buildings between commercial and housing activities). However, spatial metrics are only able to capture the horizontal variability of land uses. This makes it necessary to elaborate a new cartographic legend for each case study that represents the vertical variability of land use activities in the urban context before applying spatial metrics.

Second, spatial metrics can estimate a single value for each urban patch, land use class or urban landscape. Nonetheless, a single value is insufficient in the urban context, given its extremely high spatial heterogeneity. To overcome this, authors have used specific methodological approaches for applying spatial metrics based on both urban transects (e.g. Pham et al., 2011; Yang et al., 2010) and buffering zones around the urban centre (Ji et al., 2006; Xu et al., 2007). Nevertheless, in the last years, the use of moving-window metrics seems to be a more adequate solution to this problem. In the case of moving-window metrics, the spatial unit of calculation is each pixel, facilitating the study of contexts with very high spatial heterogeneity (Figure 1).

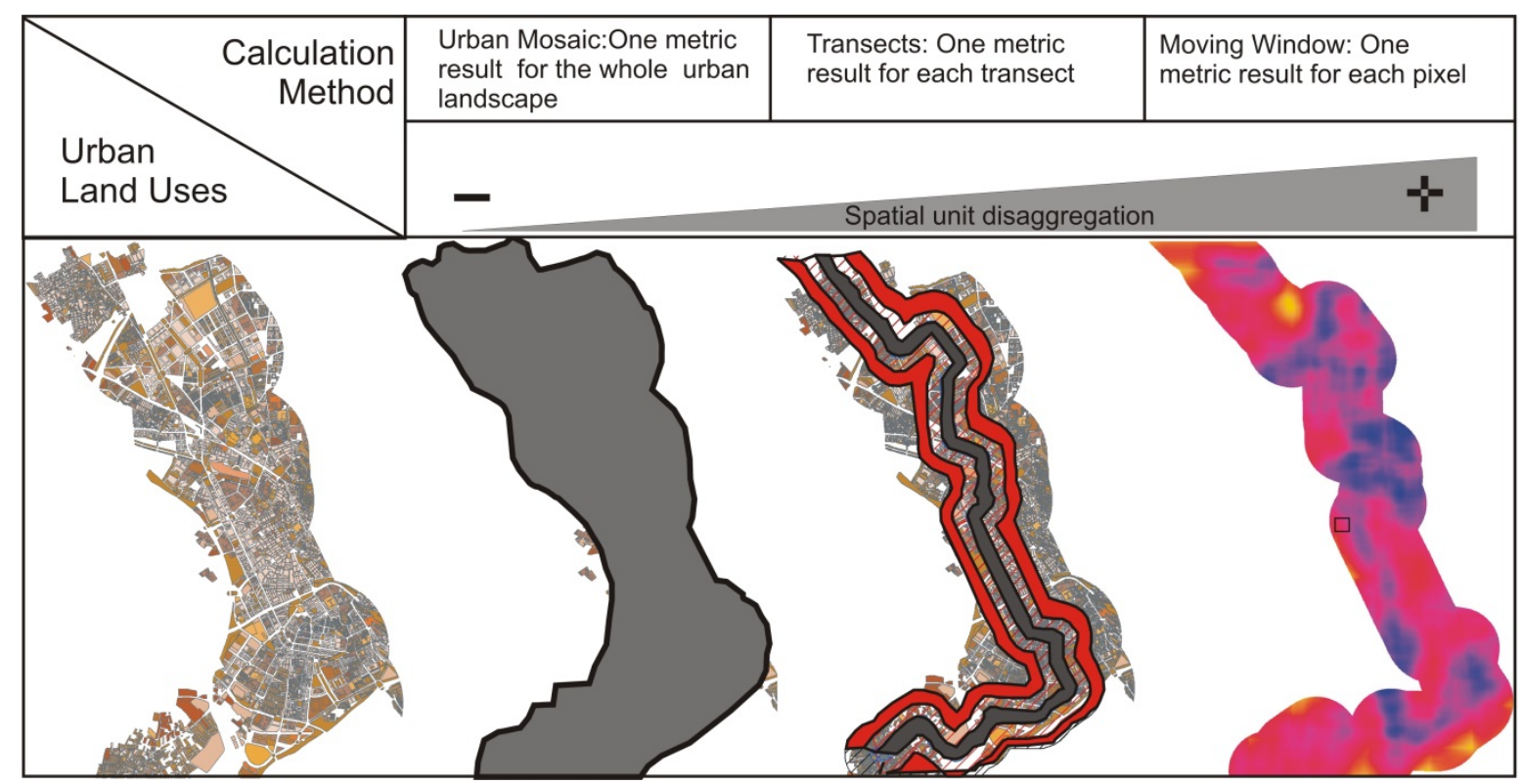

Figure 1. Illustrating methods for applying spatial metrics in urban contexts 
Moving-window metrics are based on a Kernel that passes over every positivelyvalued cell in the grid dataset, estimating a spatial metric value based on the land use activities under the window. Furthermore, the moving-window method enables the generation of continuous grid maps from each processed spatial metric (Pham et al., 2011) that can be used during LUT strategy-making. The latest can also facilitate the interaction of the different professional groups due to abstract spatial concepts can be easily translated into graphical and intuitive schemes. 


\section{Research method}

\subsection{Case study, LUT strategies and cartographic sources}

The transport corridor in the Metropolitan Area of Granada (MAG), located in southern Spain (Figure 2), served as the case study. Since the 1970s, MAG has been undergoing a significant urban transformation, with an origin in an intense growth in real estate development, the creation of new transport infrastructures, and the growth of the private vehicle market (Aguilera et al., 2010; 2011). In parallel, the environmental impacts associated with urban transportation (e.g. congestion, air pollution, respiratory and health problems, etc.) have become more prominent (Soria-Lara, 2012; Soria-Lara and Valenzuela-Montes, 2014).

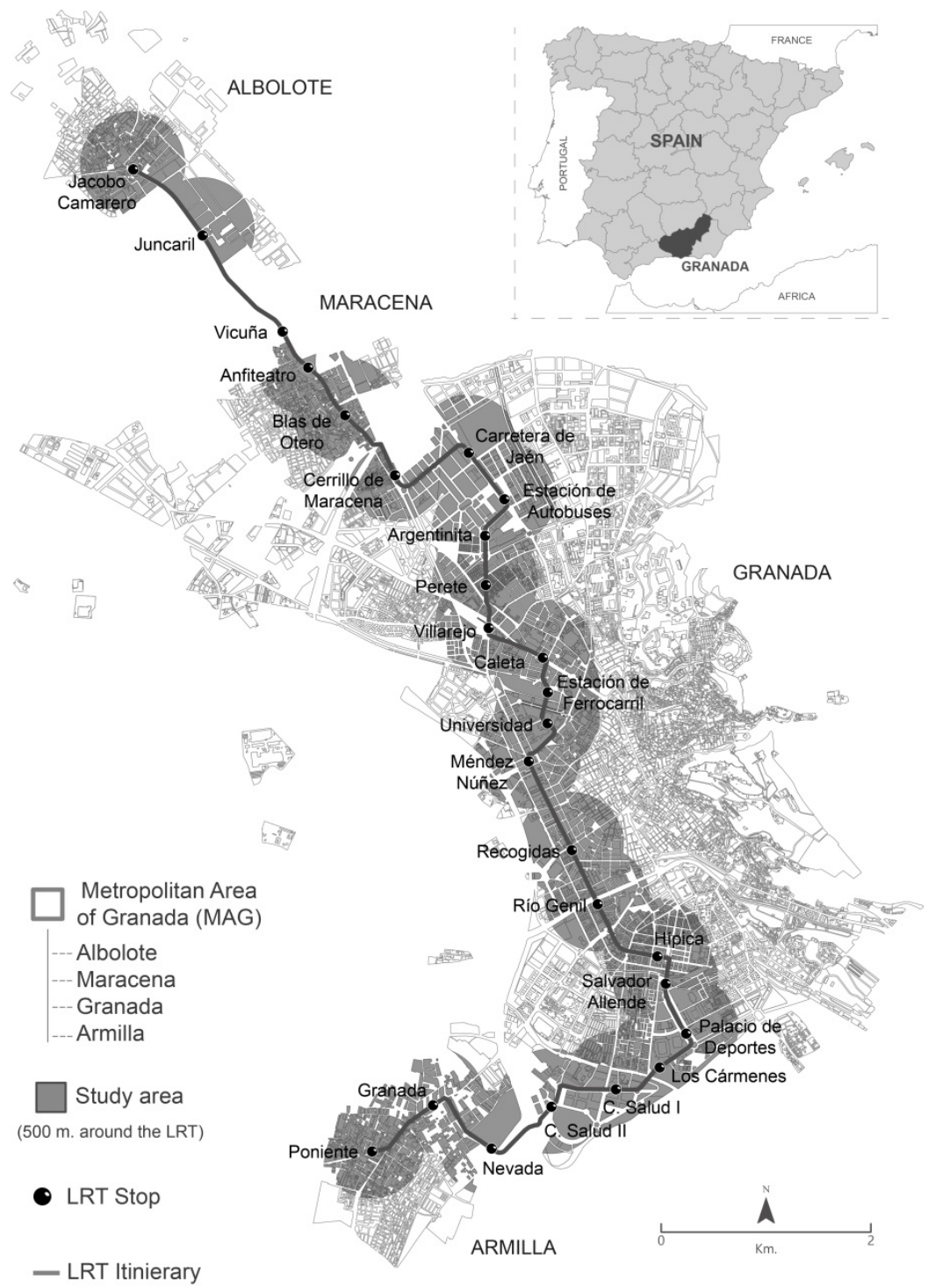

Figure 2. LRT corridor in the Metropolitan Area of Granada 
To reduce these impacts and promote sustainable mobility patterns, regional and local institutions decided to implement a LRT along the main transport corridor, made up of 4 municipalities: Albolote, Armilla, Granada and Maracena. Furthermore, they sought to initiate a strong urban transformation within a $500 \mathrm{~m}$ radius around LRT stations, based on locating the corridor using three LUT strategies: (i) proximity dynamics and non-motorised modes; (ii) modal shift from cars to LRT; (iii) shared spaces between motorised and non-motorised modes.

Spatial metrics will be used to locate and map the aforementioned LUT strategies on the LRT corridor. To address this, each LUT strategy will be mapped according to three land use characteristics interrelated with the local transport system (Figure 3):

i) Land use mixing or the closeness and mixing of the land use activities.

ii) Land use diversity or the likelihood of finding different land use activities in a specific place, although land use activities are not necessarily well-mixed

iii) Green areas connectivity or the contiguity of green areas (parks, boulevards, etc.) in a specific place.

The first LUT strategy, "proximity dynamics and non-motorised modes", means the understanding of a mobility space as a place where short-distance travels are predominant and the population can spend time and interact, rather than only transiting. In such places, land use mixing, land use diversity and green areas connectivity are expected to have very high values, and motorised transport should not be an essential mode. This LUT strategy would encourage investment in upgrading the quality of green areas as well as promoting new facilities and commercial activities (small shops, bars, spaces for children, etc.). The second LUT strategy is inspired by promoting a "modal shift from cars to LRT". The idea would be to identify places around the corridor where high values of land use mixing, land use diversity and green areas are not relevant, as well as where motorised transport modes are predominant. The main aim of this LUT strategy would be to keep these places as spaces focused on motorised traffic, but encouraging a "modal shift", for example through park-and-ride systems. Finally, the third LUT strategy is based on identifying "shared spaces between motorised and non-motorised modes". In such places, values of land use mixing, land use diversity and green areas connectivity 
should be in between the two previous LUT strategies. It is aimed at designing more friendly transport infrastructure for both motorised and non-motorised modes (e.g. multimodal public transport stations; multimodal street design, etc.).

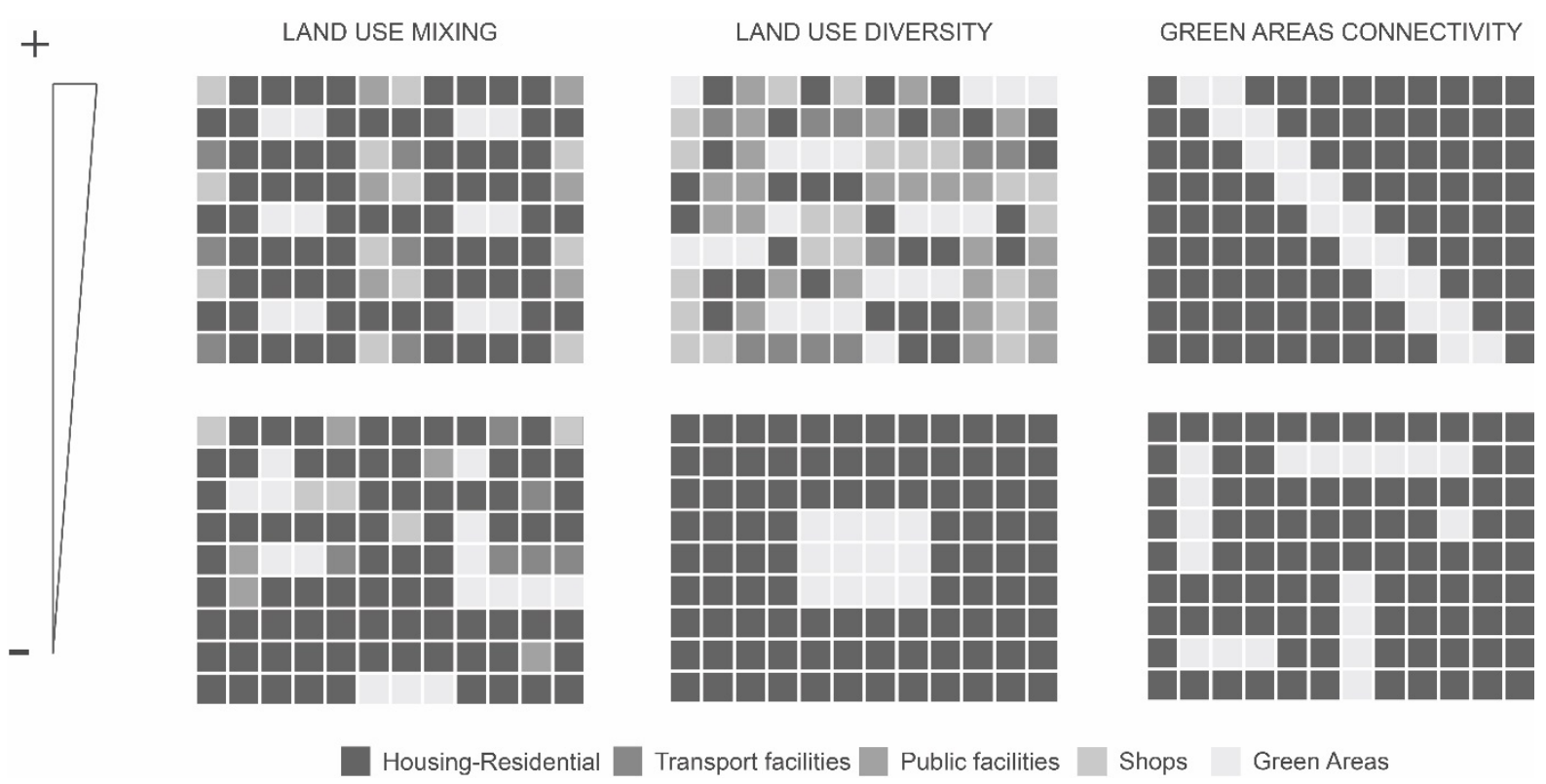

Figure 3. Land use characteristics for LUT strategies

Spatial metrics will be applied to an area of $500 \mathrm{~m}$ around the LRT itinerary, according to both the decay-distant effect of LRT in urban contexts, as recommended by several authors (see Hass-Klau and Crampton, 2002; Vuchic, 2005), and the dimension of the area recommended by local institutions involved in LUT strategy-making with context information on the LRT project. Land uses datasets from the municipalities' official database were used during the analysis. The date of the datasets is 2013. They provided us with information on housing, mixed housing (housing and commercial activities), industrial facilities, intermodal facilities, sport facilities, cultural facilities, institutional facilities, health care facilities, educational facilities, commercial facilities, green spaces and non-specified areas. 


\subsection{Selection of spatial metrics}

As indicated, spatial metrics will measure the three spatial characteristics (land mixing, land use diversity and green areas connectivity) that will help us to map and determine which areas are more suitable for each of the described LUT strategies.

The selection of spatial metric was based on the catalogue of the free software FRAGSTATS 4.2 (Table 1). As the calculations of both land use mixing and land use diversity are affected by the full spectrum of land use activities considered in this study, the catalogue of spatial metrics at "landscape/mosaic level" was used in this respect. However, as green areas connectivity is only affected by green spaces, the catalogue of spatial metrics at "class level" was used in this case. Two specific boundary conditions were followed in order to select the spatial metrics from the FRAGSTATS catalogues: (i) User-friendly metrics to reinforce the transfer of knowledge from academia to practice; (ii) Intuitive interpretation of the spatial metrics' results.

First, since land use mixing refers to the closeness and mixing of land use activities, the spatial metric interspersion and juxtaposition index (IJI) was selected (Table 1). Higher IJI values show that distances between land use activities are more homogenous and shorter. Second, Shannon diversity Index (SHDI) was selected to measure land use diversity. Higher Shannon values mean a greater number of different land use activities in a specific space. Third, the spatial metric aggregation index (Al) was selected to study the land use characteristic of green areas connectivity. Again, higher Al values mean higher contiguity of green places for transiting. 
Table 1. Detailed description of the selected spatial metrics (based on McGarigal et al., 2012)

\begin{tabular}{|c|c|c|c|c|}
\hline $\begin{array}{c}\text { Land use } \\
\text { characteristics }\end{array}$ & $\begin{array}{l}\text { Spatial } \\
\text { metric }\end{array}$ & Equation & Unit & Description \\
\hline Land use mixing & $\begin{array}{l}\text { Interspersion } \\
\text { and } \\
\text { juxtaposition } \\
\text { index (IJI) }\end{array}$ & $\begin{array}{l}I J I=\frac{-\sum_{k=1}^{m}\left[\left(\frac{e_{i k}}{\sum_{k=1}^{i k} e_{i k}}\right) \ln \left(\frac{e_{i k}}{\sum_{k=1}^{i k} e_{i k}}\right)\right]}{\ln (m-1)} \\
\text { where } \mathrm{e}_{i k} \text { is the total length }(\mathrm{m}) \text { of the edge } \\
\text { in landscape between patch types (classes) } \\
\text { i and k. On the other hand, } \mathrm{m} \text { is the number } \\
\text { of patch types (classes) present in the } \\
\text { landscape, including the landscape border, } \\
\text { if present. }\end{array}$ & Percent & $\begin{array}{l}|J| \geq 0 \text {. } \\
|J| \text { equals minus the sum of the length }(\mathrm{m}) \text { of each unique } \\
\text { edge type involving the corresponding patch type divided } \\
\text { by the total length }(\mathrm{m}) \text { of edge }(\mathrm{m}) \text { involving the same type, } \\
\text { multiplied by the logarithm of the same quantity, summed } \\
\text { up over each unique edge type; divided by the logarithm of } \\
\text { the number of patch types minus } 1 \text {; multiplied by } 100 \text { (to } \\
\text { convert to a percentage). In other words, the observed } \\
\text { interspersion over the maximum possible interspersion for } \\
\text { the given number of patch types. }\end{array}$ \\
\hline $\begin{array}{l}\text { Land use } \\
\text { diversity }\end{array}$ & $\begin{array}{l}\text { Shannon } \\
\text { diversity } \\
\text { index } \\
\text { (SHDI) }\end{array}$ & $\begin{array}{l}S H D I=-\sum_{i=1}^{m}\left(P_{i} * \ln P_{i}\right) \\
\text { where } P_{i} \text { is the proportion of the landscape } \\
\text { occupied by patch type (class) } \mathrm{i} \text {. }\end{array}$ & None & $\begin{array}{l}\text { SHDI } \geq 0 \text {. } \\
\text { It increases as the number of different patch types } \\
\text { increases and/or the proportional distribution of area } \\
\text { among patch types becomes more equitable. }\end{array}$ \\
\hline $\begin{array}{l}\text { Green areas } \\
\text { connectivity }\end{array}$ & $\begin{array}{l}\text { Aggregation } \\
\text { index } \\
\text { (AI) }\end{array}$ & $\begin{array}{l}A I=\left[\frac{g_{i i}}{\text { maxg }_{i i}}\right] 100 \\
\text { where } g_{i i} \text { is the number of like adjacencies } \\
\text { (joints) between pixels of patch type (class) } \\
\text { i based on the single-count method; max } g_{i i} \\
\text { is the maximum number of like adjacencies } \\
\text { (joints) between pixels of patch type (class) } \\
\text { i based on the single-count method. }\end{array}$ & Percent & $\begin{array}{l}\text { Al increases as the focal patch type is increasingly } \\
\text { aggregated and equals } 100 \text { when the patch type is } \\
\text { maximally aggregated into a single, compact patch. }\end{array}$ \\
\hline
\end{tabular}

\subsection{Application of spatial metrics: the moving-window method}

We employed the moving-window method (Diaz-Varela et al., 2009). A rectangular window was passed over every cell in the grid dataset (all cells inside the $500 \mathrm{~m}$ around the LRT were of interest. See Section 3.1). Within each window, each selected metric is computed and the value returned to the focal (centre) cell. Every central pixel of the output thematic map records a metric value of land use mixing, land use diversity and green areas connectivity. New thematic maps were produced during the analysis, showing the results from spatial metric (Figure 4). 


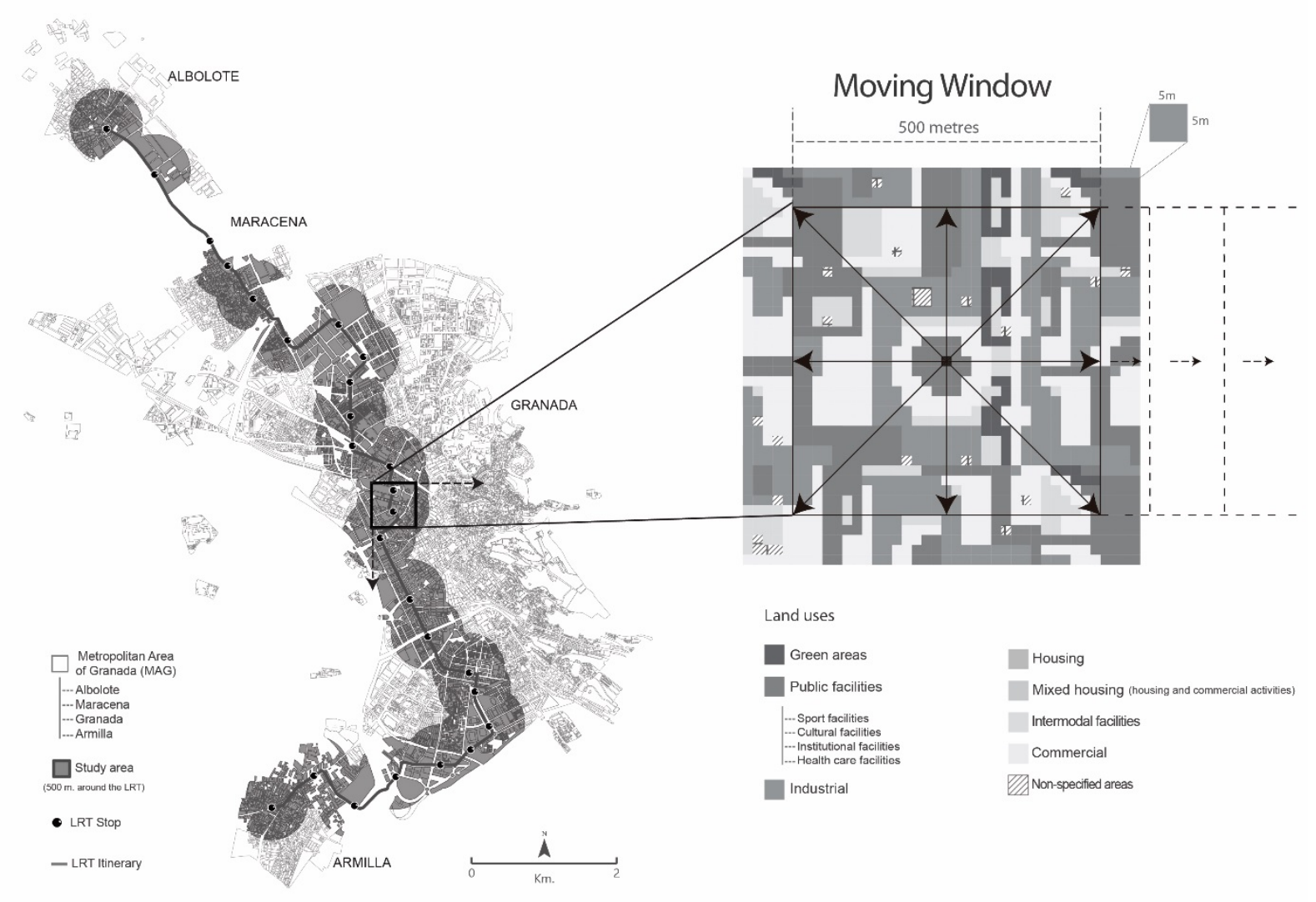

Figure 4. Moving-window method applied to the Granada case study

A methodologically crucial issue in using the moving-window computed metrics is the window size (Diaz-Varela et al., 2009). The use of different window resolutions (e.g. Wu et al., 2011) or even different scale maps (Aguilera et al., 2014) can affect the results obtained from the selected spatial metrics; therefore, the smallest possible window size should be applied in order to limit the scale dependency of the results. Inspired by Diaz-Varela et al. (2009), the spatial metric SHDI was used to determine the window size.

The dissimilarity ( $\mathrm{S}$ ) observed between the maps obtained from different windows sizes $(100 \mathrm{~m}, 200 \mathrm{~m}, 300 \mathrm{~m}, 400 \mathrm{~m}$ and $500 \mathrm{~m})$ was analysed using the following equation:

$$
S=\frac{M_{500}-M_{i}}{\left[\operatorname{Perc}_{75-500}-\operatorname{Perc}_{25-500}\right]}
$$


where $M_{500}$ is the median value of SHDI index for a map generated with a $500 \mathrm{~m} \varnothing$ window; $\mathrm{Mi}_{\mathrm{i}}$ is the median value of SHDI index for a map generated with other windows; and Perc $\mathrm{P}_{75-500}-\operatorname{Perc}_{25-500}$ is the deviation of SHDI index value for a map generated with a $500 \mathrm{~m} \varnothing$ window. Because $S$ expresses the difference among the results obtained, the observation of marked changes in S indicates differences in the response of spatial metrics to the window size. Changes in the values of $\mathrm{S}$ were studied according to the following equation:

$$
\mathrm{p}_{\mathrm{i}}=\left|\frac{\Delta \mathrm{V}_{\mathrm{i}}}{\Delta \mathrm{W}_{\mathrm{i}}}\right|-1
$$

$\Delta V_{i}$ is the percentage increase in the values of $S$ with respect to its maximum value with each change in window size (hence, the change in scale); $\Delta \mathrm{W}_{\mathrm{i}}$ is the percentage increase in moving window sizes, and $i$ is each increment in scale. $P_{i}$ shows the variation of the slope of the curve of $S$, hence $p_{i}>0$ would imply a variation in dissimilarity that is more than proportional with respect to scale (window size), and $\mathrm{p}_{\mathrm{i}}$ $<0$ is a variation that is less than proportional with respect to scale. Thus, at least two different domains of scale could be defined: one domain in which pi $>0$, where the moving window only detects local effects, and furthemore is very scale dependent, and another domain in which $\mathrm{p}_{\mathrm{i}}<0$, where the heterogeneity trend is progressively less dependent on window size, thus showing a tendency towards self-similarity in the response of heterogeneity across scales.

In sum, the change in the tendency of pi would determine the minimum window size. In our particular case study, $p_{i}$ was $<1$ for a moving-window size of $400 \mathrm{~m}$ (p400 = 0.05). This means that the minimum moving-window size to avoid effects associated with high scale dependency is $400 \mathrm{~m}$. Since the analysis of spatial metrics that cover an area around the corridor is equivalent to $500 \mathrm{~m}$, due to the decay-distant effect of LRT in urban contexts (Hass-Klau and Crampton, 2005; Vuchic, 2005), the moving window size was finally set at $500 \mathrm{~m}$.

\subsection{The identification and mapping of LUT strategies on LRT corridor}

The data analysis included frequency analysis and non-parametric descriptive tests. During the first step, frequency analyses distributed the values for each spatial 
metric into three groups of percentiles: i) values<perc.25 for low values; ii) perc.25>values<perc.75 for medium values; iii) values>perc.75 for high values.

Subsequently, the application of "If...Then..." rules on the obtained results identified suitable locations on the corridor for each of the three LUT strategies. When the results of two of the three considered spatial metrics were high (>perc.75), these locations would be classified as suitable for the strategy based on "proximity dynamics and non-motorised modes". When the results of two of the three spatial metrics were low (<perc.25), those spaces would be classified as suitable for promoting a "modal shift from cars to LRT". Lastly, when the results of two of three spatial metrics were neither high (>perc.75) nor low (<perc.25), these locations are deemed suitable as "shared spaces between motorised and non-motorised modes"

\subsection{Methods for the validation of spatial metrics}

The validation of the usability and outcomes of the spatial metrics will be based on the active involvement of practitioners. This part of the research focuses on responding to questions such as: could spatial metrics work (or they could not work) in transport practice? and why. Based on the experiences and reflections of practitioners, we can further discuss the main strengths and shortcomings of spatial metrics in the case study.

To address this, both surveys and semi-structured interviews with practitioners were conducted (Bryman, 2008). In total, 10 practitioners were asked to participate in this phase of the research. They were divided into 3 groups: (i) transport planners (4 participants); (ii) land use planners (4 participants); (iii) Policy-makers (2 participants). Aspects such as age and the level of experience in the field were taken into consideration in order to preserve the right variability. The participation of each practitioner consisted of:

(i) Phase 1 - Pre-interview and "ex-ante" survey: stakeholders were contacted by researchers twice (via telephone, skype and e-mail). First, the research and the interview themes were introduced to them. Second, they filled out an "ex-ante" survey on the use of traditional spatial indicators without using spatial metrics. The content of the "ex-ante" survey can be consulted in Appendix A. 
(ii) Phase 2 - Training session (15-20 min): Researchers showed practitioners what spatial metrics are and how they could be included in transport practice. To do that, a video (prepared for the particular case) and illustrations from mobility-plans in the context of Spain were used as support material².

(iii) Step 3 - Interview (20-25 min): Researchers asked practitioners to respond to a set of generic questions related to the spatial metrics' usability in the transport sector, as well as their outcomes in the context of Granada. Clarifications of why and how were also made in order to focus the participants' responses on the main aim of the research. Specifically, the following five general questions were formulated:

a. General perception: What is your general perception of the effectiveness of spatial metrics in transport practice?

b. Usability: How usable can spatial metrics be in transport practice?

c. Outcomes: Do you think that the outcomes of spatial metrics have mapped appropriately the land use characteristics such as land use mixing, land use diversity and green areas connectivity in the context of Granada? And in the context of LUT strategies?

d. Final remarks: What are the main strengths and weakness that you have perceived?

(iv) Step 4 - "Ex-post" survey: participants filled out an "ex-post" survey on the potential of spatial metrics in the current state of transport practice. The content of the "ex-post" survey can be consulted in Appendix A.

Two complementary types of measures were employed to validate the spatial metrics: (i) the comparison between "ex-ante" and "ex-post" surveys summarising and ranking the participant's perceptions; (ii) an in-depth discussion with participants about their experiences of the process. The combination of these two complementary types of measures provides us with the construction of narratives on the usability and the outcomes of spatial metrics in the case study.

\footnotetext{
${ }^{2}$ A translation into English from the original video (in Spanish) used during the validation of spatial metrics can be consulted in the following link: https://goo.gl/pfVOES
} 


\section{Results}

\subsection{Results according to each spatial metric}

The first spatial metric to be analysed was the Interspersion and juxtaposition index $(I J I)$. It was used to explore the land use mixing on the LRT corridor. IJI is measured in percentages (Figures 5 and 6 ). The median of $\mid \mathrm{JI}$ in the corridor was $43.2 \%$, the perc. 25 was $32.5 \%$ and the perc. 75 was $51.8 \%$. The lowest $|\mathrm{J}|$ values (IJI < perc.25 were found in locations that displayed either very strong residential activities or a weak mix of residential with other land use activities. The density of dwellings in these areas was the highest in the entire corridor (between 95 and 300 dwellings/Ha). Two relevant patterns were identified: i) places with the lowest $|J|$ values in the municipality of Granada were located more than $200 \mathrm{~m}$ from a LRT stop; ii) places with the lowest IJI values in the other municipalities (fundamentally, Maracena and Armilla) were located at distances of less than $200 \mathrm{~m}$ from a LRT stop. This finding can be explained with the layout of the LRT, the Municipality of Granada tried to optimise the location of LRT stops in places where the population can reach a wider range of activities at shorter distances. However, the criterion followed by the funding institutions in the other municipalities was to connect their town centre (fewer land use activities, but more residents) with the municipality of Granada (the administrative capital of the region). The town centres of Maracena (LRT stops Anfiteatro and Blas de Otero) and Armilla (LRT stops Nevada and Granada) are such examples, along with the LRT stops Caleta and Recogidas in the centre of the transport corridor in the municipality of Granada. Second, the highest $|\mathrm{J}|$ values $(\mathrm{IJI}>$ perc.75) were mainly located in the municipalities of Granada and Albolote. In both municipalities, the obtained results were higher than its perc.75 in distances shorter than $200 \mathrm{~m}$ to LRT stops. This is especially significant for the Campus de la Salud stops, which have the highest concentration of land use activities accessible on foot (LRT stops Los Carmenes, Campus Salud I and Campus Salud II).

The second spatial metric is the Shannon diversity Index (SHDI) which was used to measure land use diversity (Figures 5 and 6). SHDIhas no specific units. The median of SHDI in the corridor was 1.24, the perc.25 was 0.95 and the perc.75 was 1.47. As did occur with IJI, SHDI had its lowest values (SHDI < perc.25) in the municipalities 
of Maracena and Armilla, at distances shorter than $200 \mathrm{~m}$, where the density of dwellings was always higher than 128 dwellings/Ha and the percentage of commercial facility activities was lower than $23 \%$. However, in the municipalities of Albolote and Granada, values of SHDI < perc.25 were scarcely found. In these places, the density of dwellings was always between 60 and 150 dwellings/Ha and the percentage of commercial facility activities was higher than $30 \%$. Regarding the values of SHDI > perc.75, these values were found fundamentally in the city of Granada, mainly concentrated around the LRT stops Villarejo and Caleta, which are close to public facilities with important presence (e.g. hospitals, public administration and government offices, schools, university campus, etc.) and commercial activities (e.g. small shops, bars, etc.). Other important locations along the corridor, where SHDI showed values higher than its perc.75, were between the LRT stops Hípica and Campus de la Salud. This can be explained by the high concentration of commercial activities (small and large shops and leisure venues such as bars and sports facilities), as well as the incremental expansion of the university into the socalled Campus de la Salud over the past year.

The third and last spatial metric was the green areas aggregation index (Al), which analysed the connectivity of green areas, measured in percentages (Figures 5 and 6). The median of $\mathrm{Al}$ in the corridor was $84.3 \%$, the perc.25 was $81.97 \%$ and the perc.75 was 85.89\%. On the one hand, the lowest values of $\mathrm{Al}$ (Al < perc.25) were always found in the historical centres of the 4 municipalities (Albolote, Armilla, Granada and Maracena) where the density of dwellings is the highest in the corridor (>125 dwellings/Ha), for example, around the LRT stations Jacobo Camarero, Anfiteatro, Estación Renfe and Poniente. This is mainly due to the fact that the promotion of green areas in the historical cities has been limited by the existing built environment in the municipalities. The highest $\mathrm{Al}$ values ( $\mathrm{Al}>$ perc.75) were found in areas developed from the 1970s onwards, when green areas and the city's environmental qualities became much more important. The highlighted LRT stops included Palacio de Deportes and Campus de la Salud in the south of the Granada municipality, as well as in the north of the city around the LRT stop Cerrillo de Maracena 

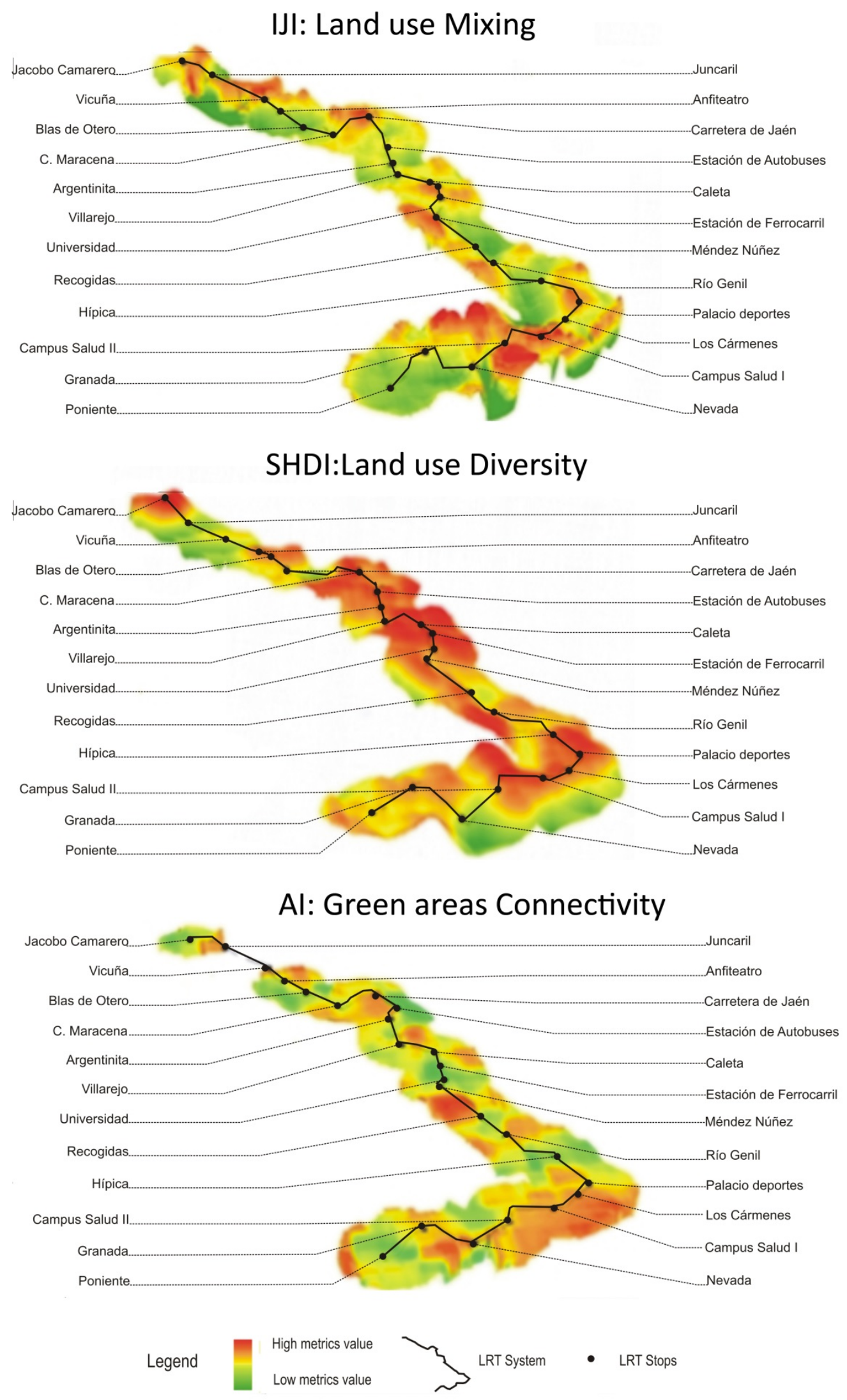

Figure 5. 3-D representation of the obtained results for each spatial metric 


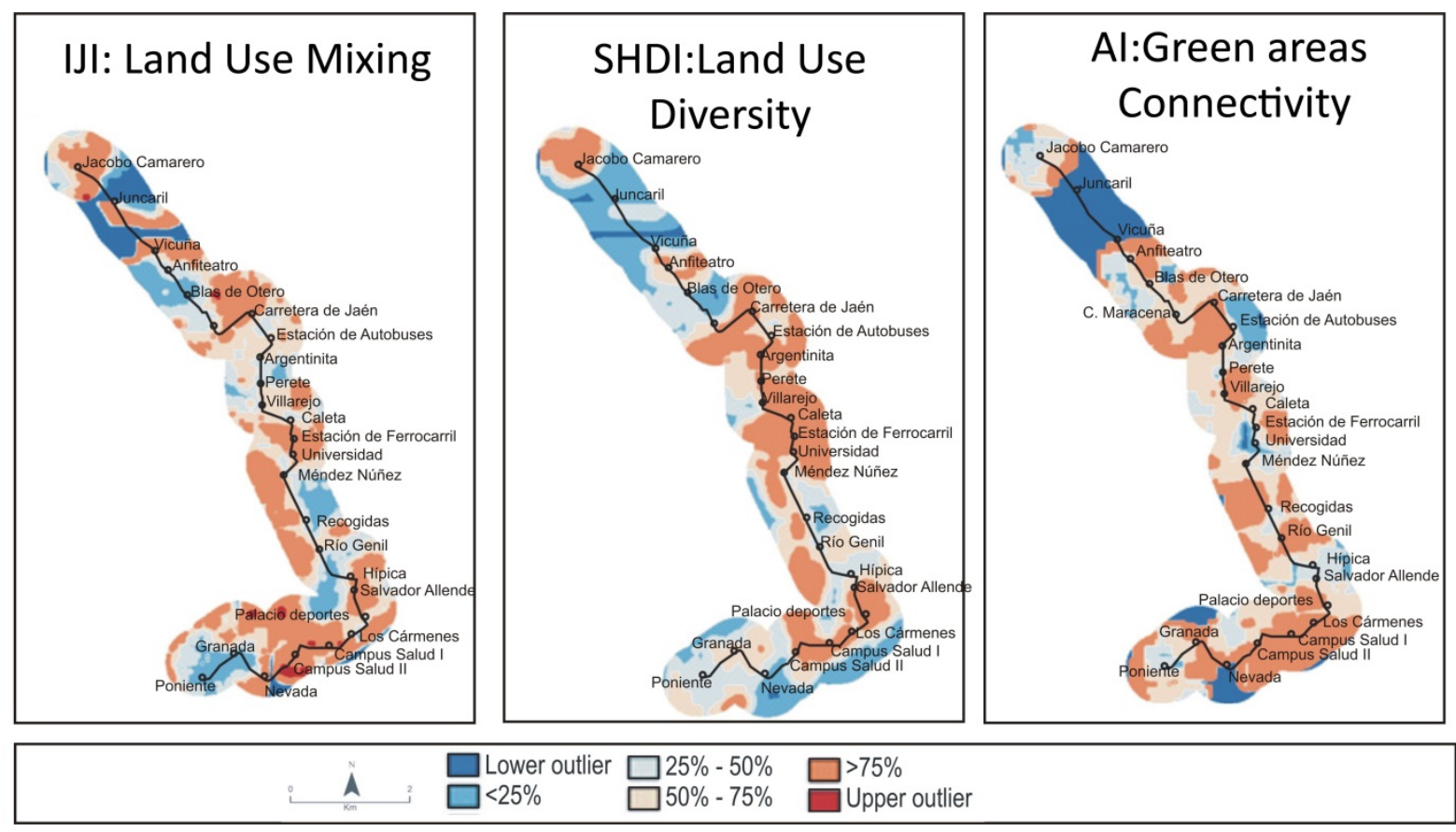

Figure 6. Frequency analyses distributed into three percentile groups

\subsection{Identification of locations for the LUT strategies}

The obtained results from each spatial metric were combined using the "If...Then" rules (see section 3), allowing us to map the suitable areas according to the following three LUT strategies: (i) proximity dynamics and non-motorised modes; (ii) modal shift from cars to LRT; (iii) shared spaces between motorised and non-motorised modes. Figure 7 summarises the obtained results.

Suitable locations for "proximity dynamics and non-motorised modes" were found around the LRT stops Jacobo Camarero (municipality of Albolote), between the stops Cerrillo de Maracena and Estación de Autobuses, between the stops Mendez Nunez and Rio Genil, and between the stops Palacio de los Deportes and Campus de la Salud (municipality of Granada). In these places, residents can cover the majority of their daily needs (working, shopping, leisure, etc.) on foot or with public transport. Cars and other motorised transport are not essential and walking could become a recurrent activity as a travel mode. With green spaces and low levels of air pollution, these locations provide children and aged people with good conditions for leisure and socialising activities. 

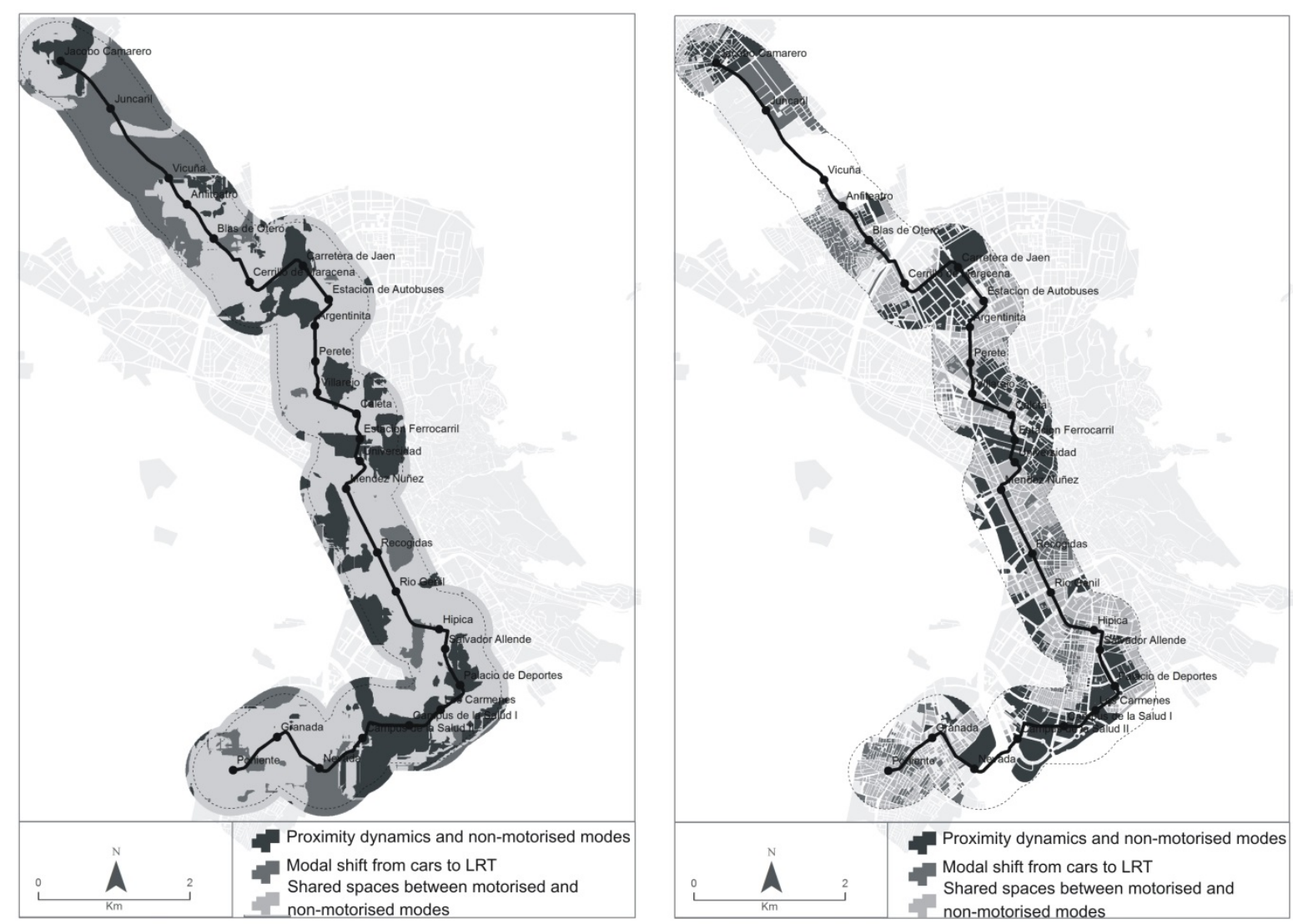

Figure 7. Strategies mapped through spatial metrics results. Left: grid dataset from the combination of spatial metrics following "If..then..." rules. Right: translation of the mentioned grid dataset into the urban configuration of the case study

Two main areas were identified for the "modal shift from cars to LRT", located at the north (municipalities of Albolote and Maracena) and south portion of the corridor (municipality of Armilla). The former is around the LRT stops Juncaril and Anfiteatro, while the latter is around the stations Nevada and Poniente. Essentially, these are purely residential places where people can meet their daily-shopping needs with difficulty. The absence of open spaces, poor air quality, and high noise levels, make these areas less desirable for leisure activities.

The third transport strategy, "shared spaces between motorised and non-motorised modes", would be applied in all other areas that are not covered by the previous two strategies. It is especially relevant in the municipalities of Maracena and Armilla (the LRT stops Blas de Otero and Poniente), as well as in some parts of the city of Granada (LRT stops Argentinita and Villarejo). Both a reduction of traffic as well as promotion of pedestrian and cycling infrastructure would be pursued. 


\subsection{The validation of spatial metrics according to the perception of the practitioner}

\section{GENERAL PERCEPTION}

The findings from the practitioners' views showed different results on the usability and outcomes of spatial metrics (Figure 8). A vast majority of participants (80\%) agreed that the incorporation of spatial metrics in the transport decision-making process could be very promising to achieve a more effective integration of land use and transport. In the voice of practitioners, "spatial metrics seem to be more effective than the traditional method used in daily practice. In particular, spatial metrics can provide us with a useful instrument to study very relevant land use characteristics for designing LUT strategies, which are frequently unexplored in daily practice, such as: land use mixing and land use diversity". The group of transport planners were the most enthusiastic in this respect, highlighting that "the grids generated by spatial metrics were very intuitive, facilitating a better understanding of urban phenomena associated to transport planning". However, the group of policy-makers seemed to be the most sceptical on the potential incidence of spatial metrics to successfully integrate land use and transport, signalling that "although spatial metrics showed very accurate information on the case study's land use characteristics, traditional indicators, e.g. buffers to public transport stations, can provide us with a similar knowledge on land use characteristics impacting on the transport sector." Meanwhile, the group of urban planners signalled that "the potential of spatial metrics is during earlier phases of the transport planning process, when strategic decisions should be taken into consideration".

\section{THE USABILITY OF SPATIAL METRICS}

The usability level of spatial metrics received the lowest rating by practitioners (Figure 8). In total, 70\% participants agreed that traditional indicators were more user-friendly than spatial metrics were. Four main shortcomings can be summarised among participants' views. First, more than $60 \%$ of participants highlighted that the cartographic sources provided by institutions had to be manipulated before the application of spatial metrics. This was a consequence of the vertical variability of land use activities in urban areas, impeding a straightforward use of spatial metrics. Second, for $85 \%$ of practitioners it seemed problematic that specific free software was needed to process the spatial metrics, even though the used software was totally free. Third, $70 \%$ of participants saw the spatial metrics catalogue as having 
too much complexity, reclaiming a specific catalogue that exclusively incorporates useful spatial metrics for transport practice. Fourth, it was perceived that the application of spatial metrics in transport practice could be a highly time-consuming process.

\section{THE OUTCOMES OF SPATIAL METRICS}

The participants' views showed different results on the consideration of the outcomes of spatial metrics (Figure 8). While the grids of land use mixing and land use diversity were highly rated by more than $70 \%$ of participants, the grid of green areas connectivity received the lowest rating. Nevertheless, a vast majority of participants (80\%) agreed that the three spatial metrics used were very appropriate for the study of land use mixing, land use diversity and green areas connectivity, as well as they recognised that the areas mapped by each strategy corresponded quite well to the real context of the Granada LRT corridor. Most of the participants signalled that "spatial metrics seemed to be a very relevant contribution in how to measure and map land use mixing and land use diversity, offering additional insights into the design of LUT strategies". They indicated that "although the importance of land use mixing and land use diversity is huge for LUT strategy-making, there is a lack of indicators to measure those land use characteristics. In this respect, spatial metrics can be a new and fresh approach". However, most of the participants, and fundamentally the group of urban planners, considered that "the used spatial metric to map green areas connectivity did not give any additional support to the existing indicators in daily practice". 

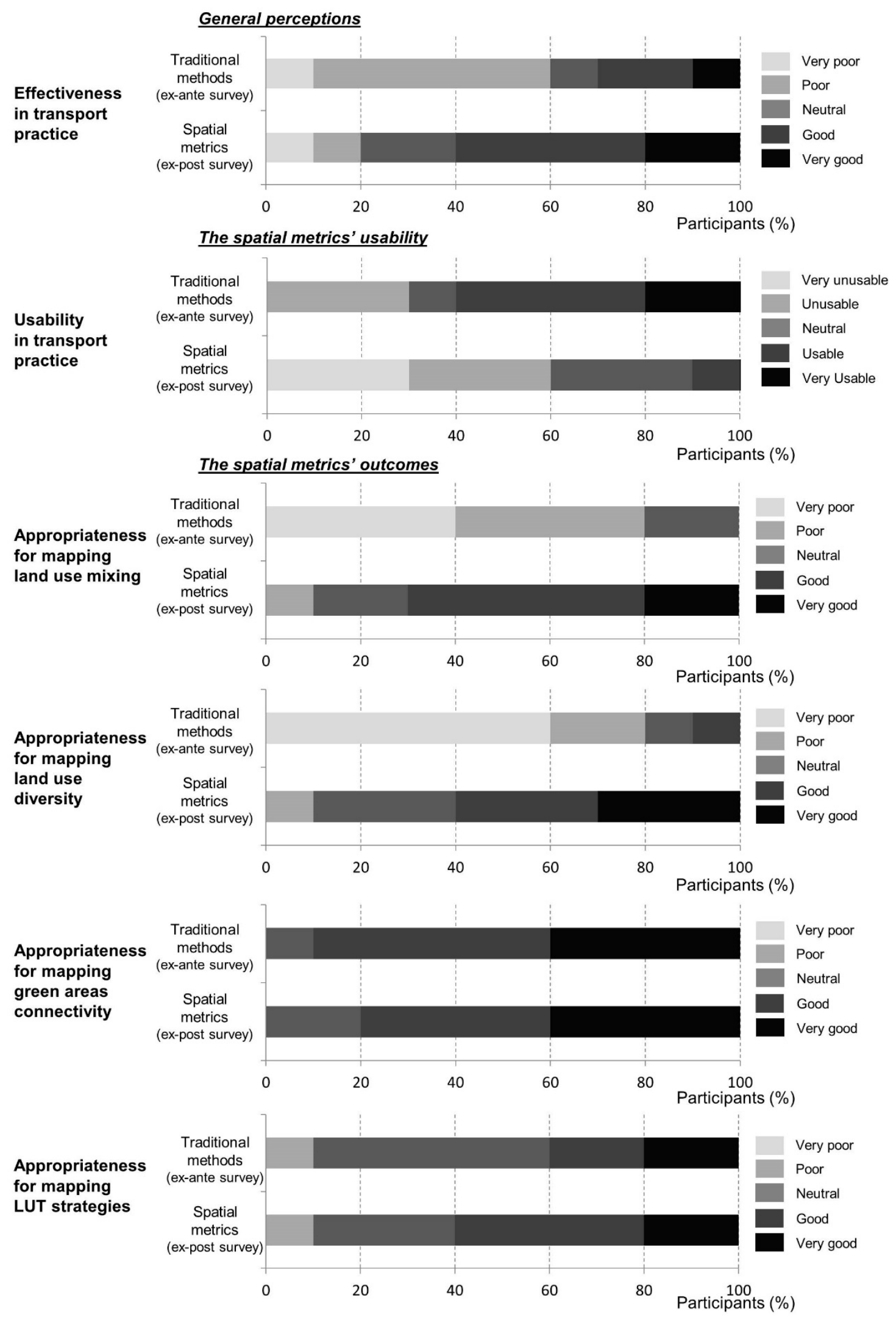

Figure 8. Practitioner perceptions of the effectiveness of spatial metrics 
Concerning the use of spatial metrics to define the following three LUT strategies: (i) proximity dynamics and non-motorised modes; (ii) modal shift from cars to Light Rail Transit system; (iii) shared spaces between motorised and non-motorised modes, more than $75 \%$ of participants agreed that the location of the three spatial metrics along the corridor "makes sense according to the real characteristic of the metropolitan area of Granada and its LRT corridor". Accordingly, they signalled that "the cited locations and the spatial metrics' results in Granada could be a good starting point for discussing more in-depth effective LUT strategies in the corridor". However, there was unanimity in saying that "the design of LUT strategies not only is dependent on land use characteristics, but other social and economic factors are also very important". In this respect, participants concluded that "spatial metrics can be one of the tools used to elaborate LUT strategies, but should not be the only one".

\section{Conclusions and discussion}

More effective actions that facilitate the integration between land use and transport should be taken sooner, rather than later, at both technical and planning process levels, as LUT visions are frequently absent in daily practice. Accordingly, this paper aimed at providing additional insights into this knowledge-practice gap by examining the following research questions: How could spatial metrics be integrated into LUT strategy-making, and how do practitioners consider their usability and outcome for spatial planning practice? Potential answers were explored by applying three specific spatial metrics (interspersion and juxtaposition index; Shannon diversity index and aggregation index for green areas) to the case study of the LRT corridor in the metropolitan area of Granada (Spain). Furthermore, practitioners were involved to assess the usability and outcomes of such spatial metrics. The obtained results described along this paper demonstrate two interesting tiers of findings: (i) the suitability of spatial metrics to translate the existing connections between land use and transport into a more intuitive language for the practitioners; (ii) the potential limitations of spatial metrics to be used in current transport practice.

First, moving-window spatial metrics proved to be a very helpful technical solution for analysing and mapping a set of land use characteristics (land use mixing, land use diversity, and green areas connectivity). Moreover, practitioners signalled how the combination of the spatial metrics' results could be very useful as a starting point to 
discuss the location of three potential LUT strategies in the LRT corridor of Granada. While an effective transfer of knowledge from academia to practice has been scarcely achieved in LUT strategy-making (e.g. Ewing and Cervero, 2012; Jones et al., 2007; Pitombo et al., 2010), an improvement in the LUT spatial perspective for transport practice was observed by practitioners through the use of spatial metrics. This is fundamentally relevant in the context of emergent communicative transport planning paradigms, based on interaction and debate between the professional groups involved (Wilson, 2001). In this respect, spatial metrics can be recognised as promising instruments to bridge the major gap between the explicit knowledge (formal education and the dominant epistemological framework) and tacit knowledge (personal experience gathered in a specific context and time) of professional groups involved in LUT strategy-making (Te Brömmelstroet and Bertolini, 2010). According to participants, spatial metrics provided end-users with both quantitative information frequently desired by transport planners- about different land use characteristics (e.g. specific quantifiers of land use patterns) and qualitative information, which is more preferred by urban planners (e.g. the spatial distribution of such spatial characteristics on the corridor). Further experiments to test how spatial metrics can reinforce a more communicative approach in transport planning would be timely and relevant.

The second tier of findings focuses on the contested usability of spatial metrics according to the practitioners' perceptions. The usability problems highlighted in the study are similar to other LUT tools, such as accessibility indicators and Planning Support Systems (e.g. Soria-Lara et al., 2015; Marquet and Miralles-Guasch, 2015; Te Brömmelstroet, 2010; Vonk et al., 2005). Firstly, one specific problem of spatial metric is how to capture the vertical variability of land use activities in urban areas. This was undertaken by the definitions within the ad hoc cartographic legend in this study. The solution was seen as a barrier by practitioners, who declared problems of subjectivity in the cartographic definition, as well as being a highly time-consuming process. Inspired by the Structural Accessibility Layer, as proposed by Silva (2013), a suggestion to improve this barrier can be the implementation of spatial metrics according to vertical layers of land uses. Those vertical layers should be later combined into a unique value.. Secondly, the need to use specific software is also seen as a crucial shortcoming for practitioners. Suggestions to overcome this aspect 
can be based on studies related to the application of Planning Support Systems to LUT strategy making (Te Brömmelstroet and Bertolini, 2008). Progress should be based on the development of a tool with the ability to be implemented in free GIS software, while being flexible, user-friendly, transparent and having high communication value. Furthermore, it seems convenient that the tool can include a catalogue of specific spatial metrics interested for LUT strategy-making. The test of the aforementioned innovations in "experiential workshops" that represent "close-toreal-life" LUT strategy-making process, as well as in real transport project across different planning systems, could provide more robust findings on the level of usability of spatial metrics.

\section{Acknowledgements}

The input by the three anonymous referees in thinking through how to improve the earlier version of our manuscript is gratefully acknowledged.

This paper has been carried out within the framework of the following research projects:

- "BACK-SCENE: Backcasting scenarios as collaborative learning process: involving stakeholders in transport climate policy", funded by European Union's Seventh Framework Programme, Marie Skłodowska-Curie actions (COFUND - Grant Agreement no. 291780) and the Ministry of Economy, Innovation, Science and Employment of the Junta de Andalucía (Spain).

-"PLOTEG: Herramientas cartográficas para una gobernanza inteligente en las ciudades digitales: Análisis territorial de las condiciones de vida", funded by Ministy of Economy and supported by European Institutions. R\&D Spanish program Grant agreement no. CSO2013-46863-C3-3-R. 


\section{References}

Aguilera, F., Valenzuela L. M. \& Bosque Sendra, J. (2010). Future scenario simulation in the metropolitan area of Granada using models based on cellular automata. Boletin de la Asociacion de Geografos Espanoles, 54, 271-300

Aguilera, F., Valenzuela L. M., \& Botequilha-Leitão A. (2011). Landscape metrics in the analysis of urban land use patterns: A case study in a Spanish metropolitan area. Landscape and Urban Planning, 99, 226-238

Aguilera, F., Botequilha-Leitao, A., \& Díaz-Varela, E., 2014. Detecting multi-scale urban growth patterns and processes in the Algarve region (Southern Portugal). Applied.Geography, 53, 234-245.

Albert, G., \& Mahalel, D. (2006). Congestion tolls and parking fees: A comparison of the potential effect on travel behavior. Transport policy, 13(6), 496-502.

Barreira González, P., Aguilera-Benavente, F., Gómez-Delgado, M (2015). Partial validation of cellular automata based model simulations of urban growth: An approach to assessing factor influence using spatial methods. Environmental Modelling and Software, 69, 77-89

Banister, D. (2005). Unsustainable transport: city transport in the new century. Taylor \& Francis.

Bertolini, L., \& Dijst, M. (2003). Mobility environments and network cities.Journal of urban design, 8(1), 27-43.

Bertolini, L., le Clercq, F., \& Straatemeier, T. (2008). Urban transportation planning in transition. Transport Policy, 15(2), 69-72.

Beukers, E., Bertolini, L., \& Te Brömmelstroet, M. (2014). Using cost benefit analysis as a learning process: identifying interventions for improving communication and trust. Transport Policy, 31, 61-72.

Bryman, A. (2008). Social research methods. Oxford university press.

Cervero, R., \& Kockelman, K. (1997). Travel demand and the 3Ds: density, diversity, and design. Transportation Research Part D: Transport and Environment, 2(3), 199219.

Cervero, R., Sarmiento, O. L., Jacoby, E., Gomez, L. F., \& Neiman, A. (2009). Influences of built environments on walking and cycling: lessons from Bogotá. International Journal of Sustainable Transportation, 3(4), 203-226. 
Curtis, C. (2011). Integrating land use with public transport: The use of a discursive accessibility tool to inform metropolitan spatial planning in Perth. Transport Reviews, 31(2), 179-197.

Diaz-Varela, E., Álvarez-López, C., \& Marey-Pérez, M. P. (2009). Multiscale delineation of landscape planning units based on spatial variation of land-use patterns in Galicia, NW Spain. Landscape Ecological Enginering, 5, 1-10.

Dietzel, C., Herold, M., Hemphill, J. J., \& Clarke, K. C. (2005). Spatio-temporal dynamics in California's Central Valley: Empirical links to urban theory. International Journal of Geographical Information Science, 19(2), 175-195

Ewing, R., \& Cervero, R. (2012). Travel and the built environment: a synthesis. Transportation Research Record: Journal of the Transportation Research Board, 1780(1), 87-114.

García, A. M., Santé I., Crecente R., \& Miranda D. (2011). An analysis of the effect of the stochastic component of urban cellular automata models. Computers, Environment and Urban Systems, 35, 289-296.

Habermas, J (2007) Classical pragmatism and communicative action; in Hickman, L. A. (2007). Pragmatism as post-postmodernism: Lessons from John Dewey (Vol. 21). Fordham Univ Press.

Hass-Klau, C., \& Crampton, G. (2002). Future of urban transport: learning from success and weakness: light rail. Brighton: Environmental and Transport Planning.

Herold, M., Goldstein, N., \& Clarke, K. (2003). The spatio-temporal form of urban growth: measurement, analysis and modeling. Remote Sensing of Environment, 85, 95-105.

Herold, M., Couclelis, H., \& Clarke, K. C. (2005). The role of spatial metrics in the analysis and modeling of urban land use change. Computers, Environment and Urban Systems, 29, 369-399

Hickman, R., \& Banister, D. (2007). Looking over the horizon: transport and reduced CO 2 emissions in the UK by 2030. Transport Policy, 14(5), 377-387.

Hrelja, R. (2015). Integrating transport and land-use planning? How steering cultures in local authorities affect implementation of integrated public transport and land-use planning. Transportation Research Part A: Policy and Practice, 74, 1-13.

Ji, W., Ma, J., Twibell, R.W., \& Underhill, K. (2006). Characterizing urban sprawl using multi-stage remote sensing images and landscape metrics. Computers, Environment and Urban Systems, 30, 861-879

Jones, P., Boujenko, N., \& Marshall, S. (2007). Link \& Place-A guide to street planning and design. 
Kaza, N. (2013). The changing urban landscape of the continental United States. Landscape and urban Planning, 110, 74-86.

Kong, F., Haiwei, Y., Nakagoshi N., \& James, P. (2012). Simulating urban growth processes incorporating a potential model with spatial metrics. Ecological Indicators, $20,82-9$

Li, X., Yang, Q., \& Liu, X. (2008). Discovering and evaluating urban signatures for simulating compact development using cellular automata. Landscape and urban Planning, 86, 177-186

Marquet, O., \& Miralles-Guasch, C. (2015). The Walkable city and the importance of the proximity environments for Barcelona's everyday mobility. Cities, 42, 258-266.

McGarigal, K., Cushman, S. A., \& Ene, E. (2012). FRAGSTATS v4: Spatial Pattern Analysis Program for Categorical and Continuous Maps. Computer software program produced by the authors at the University of Massachusetts, Amherst. http://www.umass.edu/landeco/research/fragstats/fragstats.html.

Oakes, J. M., Forsyth, A., \& Schmitz, K. H. (2007). The effects of neighborhood density and street connectivity on walking behavior: the Twin Cities walking study. Epidemiologic Perspectives \& Innovations, 4(1), 16.

Pascual-Rosa, V., Aguilera-Benavente, F., \& Salado-García, M.J. (In Progress). Towards a characterisation of the use of spatial metrics in urban form studies.

Petrov, L. O., Lavalle, C., \& Kasanko, M. (2009). Urban land use scenarios for a tourist region in Europe: Applying the MOLAND model to Algarve, Portugal. Landscape and Urban Planning, 92, 10-23. DOI:10.1016/j.landurbplan.2009.01.011

Pham, H. M., Yamaguchi, Y., \& Bui, T.Q. (2011). A case study on the relation between city planning and urban growth using remote sensing and spatial metrics. Landscape and Urban Planning, 100, 223-230

Pitombo, C. S., Kawamoto, E., \& Sousa, A. J. (2011). An exploratory analysis of relationships between socioeconomic, land use, activity participation variables and travel patterns. Transport policy, 18(2), 347-357.

Schwarz, N. (2010). Urban form revisited-Selecting indicators for characterising European cities. Landscape and Urban Planning, 96, 29-47. DOI:10.1016/j.landurbplan.2010.01.007

Seto, K. C., \& Fragkias, M. (2005). Quantifying spatiotemporal patterns of urban landuse change in four cities of China with time series landscape metrics. Landscape Ecology, 20, 871-888. 
Shrestha, M. K., York, A. M., Boone, C. G., \& Zhang, S. (2012). Land fragmentation due to rapid urbanization in the Phoenix Metropolitan Area: Analyzing the spatiotemporal patterns and drivers. Applied Geography, 32, 522-531.

Silva, C., \& Pinho, P. (2010). The Structural Accessibility Layer (SAL): revealing how urban structure constrains travel choice. Environment and Planning A, 42(11), 27352752.

Silva, C. "Structural accessibility for mobility management." Progress in Planning 81 (2013): 1-49.

Soria-Lara, J. A. (2012). Modelo de umbrales para la evaluación ambiental de la movilidad urbana. Granada: Universidad de Granada.

Soria-Lara, J. A., \& Valenzuela-Montes, L. M. (2014). Más allá de la estructura urbana y del patrón de viaje. el «entorno de movilidad» como instrumento para la planificación y la evaluación. Boletín de la Asociación de Geógrafos Españoles, 64, 273-296.

Soria-Lara, J. A., Arranz. A., \& Aguilera. F. (2014). Explorando el uso de métricas espaciales para identificar "entornos de movilidad" urbanos. In Anales de Geografía de la Universidad Complutense (Vol. 34, No. 2, pp. 185-208).

Soria-Lara, J. A., Valenzuela-Montes, L. M., \& Pinho, P. (2015). Using 'Mobility Environments' in Practice: Lessons from a Metropolitan Transit Corridor in Spain. Journal of Environmental Policy \& Planning, 17(5), 553-572.

Straatemeier, T. (2008). How to plan for regional accessibility?. Transport Policy, 15(2), 127-137.

Su, H., Wu, J. H., Tan, Y., Bao, Y., Song, B., \& He, X. (2014). A land use and transportation integration method for land use allocation and transportation strategies in China. Transportation Research Part A: Policy and Practice, 69, 329353.

Taubenböck, H., Wegmann, M., Roth, A., Mehl, H., \& Dech, S. (2009). Urbanization in India - Spatiotemporal analysis using remote sensing data. Computers, Environment and Urban Systems, 33, 179-188. DOI:10.1016/j.compenvurbsys.2008.09.003

Te Brömmelstroet, M. (2010). Equip the warrior instead of manning the equipment: land use and transport planning support in the Netherlands.Journal of transport and land use, 3(1), 25-41. 
Te Brömmelstroet, M., \& Bertolini, L. (2008). Developing land use and transport PSS: Meaningful information through a dialogue between modelers and planners. Transport Policy, 15(4), 251-259.

te Brömmelstroet, M., \& Bertolini, L. (2010). Integrating land use and transport knowledge in strategy-making. Transportation, 37(1), 85-104.

Turner, M (2005). Landscape Ecology: What Is the State of the Science? Annual Review of Ecology, Evolution, and Systematics, 36, 319-344

Van Acker, V., Witlox, F., \& Van Wee, B. (2007). The effects of the land use system on travel behavior: a structural equation modeling approach.Transportation planning and technology, 30(4), 331-353.

Vuchic, V. R. (2005). Urban Transit. Operations, planning and economics. Hoboken, NJ: JohnWiley \& Sons, Inc.

Vonk, G., Geertman, S., \& Schot, P. (2005). Bottlenecks blocking widespread usage of planning support systems. Environment and planning A, 37(5), 909-924.

Waddell, P., Ulfarsson, G. F., Franklin, J. P., \& Lobb, J. (2007). Incorporating land use in metropolitan transportation planning. Transportation Research Part A: Policy and Practice, 41(5), 382-410.

Willson, R. (2001). Assessing communicative rationality as a transportation planning paradigm. Transportation, 28(1), 1-31.

Wu, J., Jenerette, G. D., Buyantuyev, A., \& Redman, C. L. (2011). Quantifying spatiotemporal patterns of urbanization: The case of the two fastest growing metropolitan regions in the United States. Ecological Complexity, 8 , 1-8.

Xu, C., Liu, M., Zhang, C., An, S., Yu, W., \& Chen, J. M. (2007). The spatiotemporal dynamics of rapid urban growth in the Nanjing metropolitan region of China. Landscape Ecology, 22, 925-937

Yang, Y., Zhou, Q., Gong, J. \& Wang, Y. (2010). Gradient analysis of landscape spatial and temporal pattern changes in Beijin metropolitan area. Science China Technological Science, 53, 91-98. 


\section{APPENDIX A}

\begin{tabular}{|c|c|}
\hline EX-ANTE EVALUATION & EX-POST EVALUATION \\
\hline \multicolumn{2}{|l|}{ General perception on spatial metrics } \\
\hline $\begin{array}{l}\text {-Please indicate what are the main indicators/metrics } \\
\text { that you use in transport daily practice to analyse the } \\
\text { following land use characteristics: land use mixing; } \\
\text { land use diversity; green areas connectivity: }\end{array}$ & \multirow{3}{*}{$\begin{array}{l}\text { How effective can spatial metrics be in transport practice } \\
\text { to analyse land use characteristics such as: land use } \\
\text { mixing, land use diversity and green areas connectivity? }\end{array}$} \\
\hline $\begin{array}{l}\text { How effective are traditional indicators/metrics that } \\
\text { you frequently use in transport practice to analyse } \\
\text { land use characteristics such as: land use mixing, } \\
\text { land use diversity and green areas connectivity? }\end{array}$ & \\
\hline Very poor: $1223 \quad 4 \quad 5$ : Very good & \\
\hline \multicolumn{2}{|l|}{ Block 1: The usability of spatial metrics } \\
\hline $\begin{array}{l}\text { How usable are traditional indicators/metrics that you } \\
\text { frequently use in transport practice to analyse land } \\
\text { use characteristics such as: land use mixing, land } \\
\text { use diversity and green areas connectivity? }\end{array}$ & $\begin{array}{l}\text { How usable can spatial metrics be in transport practice } \\
\text { to analyse land use characteristics such as: land use } \\
\text { mixing, land use diversity and green areas connectivity? }\end{array}$ \\
\hline Very unusable: $1 \begin{array}{lllll}1 & 2 & 3 & 4 & 5 \text { : Very usable }\end{array}$ & Very difficult: $1 \begin{array}{lllll}1 & 2 & 3 & 4 & 5 \text { : Very easy }\end{array}$ \\
\hline \multicolumn{2}{|l|}{ Block 2: The outcomes of spatial metrics: } \\
\hline $\begin{array}{l}\text { How appropriate are traditional indicators/metrics that } \\
\text { you frequently use in transport practice to map land } \\
\text { use mixing? }\end{array}$ & $\begin{array}{l}\text { How appropriate are spatial metrics in transport practice } \\
\text { to map land use mixing? }\end{array}$ \\
\hline Very poor: $1 \begin{array}{lllll}1 & 2 & 3 & 4 & 5 \text { : Very good }\end{array}$ & Very poor: $\begin{array}{lllll}1 & 2 & 3 & 4 & 5 \text { : Very good }\end{array}$ \\
\hline $\begin{array}{l}\text { How appropriate are traditional indicators/metrics that } \\
\text { you frequently use in transport practice to map land } \\
\text { use diversity? }\end{array}$ & $\begin{array}{l}\text { How appropriate are spatial metrics in transport practice } \\
\text { to map land use diversity? }\end{array}$ \\
\hline Very poor: $1 \quad 2 \quad 3 \quad 4 \quad 5$ : Very good & Very poor: $1 \quad 2 \quad 3 \quad 4 \quad 5$ : Very good \\
\hline $\begin{array}{l}\text { How appropriate are traditional indicators/metrics that } \\
\text { you frequently use in transport practice to map green } \\
\text { areas connectivity? }\end{array}$ & $\begin{array}{l}\text { How appropriate are spatial metrics in transport practice } \\
\text { to map green areas connectivity? }\end{array}$ \\
\hline
\end{tabular}




\begin{tabular}{|c|c|}
\hline $\begin{array}{llllll}\text { Very poor: } & 1 & 2 & 3 & 4 & 5 \text { : Very good }\end{array}$ & $\begin{array}{llllll}\text { Very poor: } & 1 & 2 & 3 & 4 & \text { 5: Very good }\end{array}$ \\
\hline $\begin{array}{l}\text { How appropriate are traditional indicators/metrics that } \\
\text { you frequently use in transport practice to map } \\
\text { transport strategies? } \\
\text { Very poor: } \begin{array}{llllll}1 & 2 & 3 & 4 & 5 \text { : Very good }\end{array}\end{array}$ & $\begin{array}{l}\text { How appropriate are traditional spatial metrics to map } \\
\text { transport strategies? } \\
\qquad \text { Very poor: } \begin{array}{llllll}1 & 2 & 3 & 4 & 5 \text { : Very good }\end{array} \\
\begin{array}{l}\text { Which transport strategy (proximity dynamics and non- } \\
\text { motorised) }\end{array}\end{array}$ \\
\hline
\end{tabular}

